\title{
Causes of Hospitalisation Over 2011-2018 Among a Cohort of People With HIV From a London Centre
}

\section{Sophia M Rein ( $\square$ sophia.rein.17@ucl.ac.uk)}

Institute for Global Health, University College London (UCL) Royal Free Campus, Rowland Hill St London NW3 2PF https://orcid.org/00000002-5240-4838

\section{Fiona C Lampe}

University College London Institute for Global Health

\section{Clinton Chaloner}

University College London Institute for Global Health

Adam Stafford

Royal Free London NHS Foundation Trust

\section{Alison J Rodger}

University College London Institute for Global Health

\section{Margaret A Johnson}

Royal Free London NHS Foundation Trust

\section{Jeffrey McDonnell}

University College London Institute for Global Health

\section{Fiona Burns}

Royal Free London NHS Foundation Trust; University College London Institute for Global Health

\section{Sara Madge}

Royal Free London NHS Foundation Trust

\section{Alec Miners}

London School of Hygiene \& Tropical Medicine

\section{Lorraine Sherr}

University College London Institute for Global Health

\section{Simon Collins}

HIV i-Base

\section{Andrew Speakman}

University College London Institute for Global Health

Andrew N Phillips

University College London Institute for Global Health

Colette Smith

University College London Institute for Global Health

\section{Research article}

Keywords: HIV, AIDS, Hospitalization, Morbidity, Causes, Diagnoses

Posted Date: November 5th, 2020

DOI: https://doi.org/10.21203/rs.3.rs-100714/v1

License: (9) (1) This work is licensed under a Creative Commons Attribution 4.0 International License. Read Full License 


\section{Abstract}

Objective: To describe the spectrum of ICD-10 classified causes for hospitalisations occurring between 2011/2012 and 2018 in a cohort of PLHIV.

Methods: This sub-study includes 798 HIV-positive individuals participating in the Antiretroviral, Sexual Transmission Risk and Attitudes (ASTRA) questionnaire study who were recruited from a large London centre. A medical record review identified the occurrence and causes of hospitalisation from the date of questionnaire completion (2011-2012) until 1 June 2018. Up to five causes were classified by an HIV clinician using the ICD-10 system.

Results: There were 274 hospitalisations in 153 people (rate=5.8/100 person-years; $95 \%$ Cl: $5.1,6.5$ ). Causes were wide-ranging; the most common were circulatory (16.8\%), digestive (13.1\%), respiratory (11.7\%), infectious diseases (11.0\%), injury/poisoning (10.6\%), genitourinary diseases (9.9\%) and neoplasms (9.1\%). A tenth (27/274) of hospitalisations were related to at least one AIDS-defining illness. Median duration of hospitalisation was 5 days. At the time of hospitalisation, median CD 4 count was high (510 cells/ $\mu$ l; IQR: 315-739), while median CD4 nadir was relatively low (113 cells/ $\mu$ l; IQR: 40-239). At admission, half of individuals (51\%) had a previous AIDS-defining illness and $21 \%$ had viral load >50 copies/ml. Individuals admitted for infectious diseases were particularly likely to have unfavourable clinical characteristics (low CD4, viral non-suppression, not on ART, previous AIDS).

Conclusions: In the modern cART era, the spectrum of causes of hospitalisation in PLHIV in the UK is wide-ranging, highlighting the importance of holistic care for PLHIV, including prevention, early detection and treatment of comorbidities.

\section{Background}

Following the introduction of effective combination antiretroviral therapy (cART) in 1996, AIDS-related mortality and morbidity among people living with HIV (PLHIV) in high-income countries declined dramatically ${ }^{1,2}$. As life expectancy of PLHIV has continued to increase ${ }^{3,4}$, chronic conditions related to aging are increasingly prevalent ${ }^{5,6}$. This is reflected in the causes of hospitalisation among PLHIV, with non-AIDS conditions now accounting for an increasing proportion 7,8 .

Although there is previous work examining the trends over time and risk factors for hospitalisation, causes of clinical events have tended to be considered in broad categories. Monitoring the causes of hospitalisation among PLHIV in detail gives insight into changing patterns of morbidity, emerging new causes and current and future healthcare needs. However, few recent studies have comprehensively evaluated the detailed causes of hospitalisation in PLHIV in the contemporary treatment era, and, to our knowledge, none from the UK.

We describe the spectrum of ICD-10 classified causes of all hospitalisations occurring during a six-to-seven-year follow-up period, among 798 PLHIV recruited from a London centre in 2011-12.

\section{Methods}

The Antiretrovirals, Sexual Transmission Risk and Attitudes (ASTRA) questionnaire study recruited PLHIV from eight HIV outpatient clinics in England from February 2011 to December $2012^{9}$ (North West London research ethics committee 10/H0720/70). The questionnaire was developed specifically for the ASTRA study. Questionnaires for male and female participants can be found in the supplementary material.

A sub-study of hospitalisations was undertaken for participants from the Royal Free Hospital, London. Of 3,258 ASTRA participants, 899 (28\%) were recruited at the Royal Free Hospital, of whom 809 (90\%) consented to additional linkage of questionnaire data with routine clinical data ${ }^{9}$ and 798 with follow-up data available were included. Data on hospitalisations occurring from the date of questionnaire completion (2011-2012; baseline) until 1 June 2018 was obtained using routine clinic data enhanced by a detailed review of electronic and paper Royal Free hospital medical records. Information was extracted on all admissions documented (including admissions at hospitals other than the Royal Free): dates of admission and discharge, the admitting hospital, whether the admission was classified as an emergency and the causes. Causes were classified into ICD-10 codes by an HIV clinician using discharge summaries and other relevant correspondence and information documented in the notes. Up to five codes were assigned to every hospitalisation, therefore numbers can sum to more than $100 \%$. Hospitalisations were defined as overnight stays at the hospital. Repeated hospitalisations from individuals were included.

We previously reported on the association of baseline factors with subsequent hospitalisation ${ }^{10}$; this report presents the causes of hospitalisation.

\section{Results}


Of the 798 individuals, $74 \%$ were MSM, 9.5\% were heterosexual men and $16.3 \%$ were women. Median age (IQR) at baseline was 46 (40-51) years.

\section{Rates of hospitalisation}

Over a median follow-up of 6 years, 274 hospitalisations occurred in 153 people (19\%), corresponding to an overall rate of $5.8 / 100$ personyears (95\% Cl: 5.1-6.5). Overall, 206 (75\%) hospitalisations were emergencies; 223 (81\%) took place at the Royal Free Hospital. Of those hospitalised, most $(97 ; 63 \%)$ were hospitalised once, $31(20 \%)$ twice, $6(4 \%)$ three times and 19 (12\%) four or more times. The rate of subsequent admissions among those previously hospitalised was 64.2/100 person-years (95\% Cl: $52.7-75.7)$. Median time to re-admission was 237 days (IQR 54-583); 17 (18\%) re-admissions occurred within 30 days of discharge. In total, 17 (2.1\%) individuals died during followup.

\section{Causes of hospitalisation}

Of the 274 hospitalisations, 174 had one cause assigned, 69 had two, 14 had three, 9 had four, 5 had five causes and no information was available for 3 (415 causes in total). Figure 1 shows the distribution of causes.

The seven most common ICD-10 categories, which cover at least one cause for 196 (72\%) of hospitalisations, are described below.

Circulatory diseases were the most commonly documented causes, involving $16.8 \%(n=46)$ of admissions. This included: heart disease ( $n=$ 20 including: infective and acute pericarditis, mitral valve insufficiency, cardiomyopathy, cardiac arrest, cardiac arrhythmias, and heart failure); ischaemic heart disease ( $n=10$ including: angina pectoris, myocardial infarctions and chronic ischaemic heart disease); pulmonary embolism ( $n=5)$; cerebrovascular disease $(n=3)$; atherosclerosis and other diseases of the arteries/arterioles $(n=4)$; diseases of veins, lymphatic vessels and lymph nodes $(n=4)$. Other causes $(n=2)$ were chronic rheumatic heart disease (mitral valve disease) and hypertension.

Digestive diseases were the second most documented cause, present in $13.1 \%(n=36)$ of hospitalisations. Most common were diseases of: liver ( $n=8$ including: alcoholic hepatitis, hepatic failure, liver cirrhosis); gallbladder, biliary tract and pancreas ( $n=6)$; intestines ( $n=7$ including: anal abscesses, fistula of intestines, constipation, megacolon); oesophagus, stomach and duodenum ( $n=4)$; other digestive diseases $(n=7)$. There were three admissions due to non-infective enteritis and colitis, three due to acute peritonitis, two due to appendicitis, and one due to hernia.

Respiratory diseases were documented for $11.7 \%$ of admissions $(n=32)$. The specific conditions were: influenza and pneumonia $(n=20$ including: seasonal flu, bacterial pneumonia, viral pneumonia); chronic lower respiratory diseases ( $\mathrm{n}=9$ including: chronic obstructive pulmonary disease, asthma); unspecified acute lower respiratory infection $(n=5)$; other respiratory diseases ( $n=5)$; upper respiratory infections $(n=3)$.

In $11.0 \%$ of hospitalisations ( $n=30)$, infectious diseases were a documented cause. This included HIV-related infections ( $n=10$ including: mycobacterial infection, cytomegalovirus, pneumocystis jirovecii pneumonia, tuberculosis, encephalopathy, wasting syndrome, haematological and immunological abnormalities); STIs ( $n=6$ : syphilis, gonorrhoea, Chlamydia, anogenital warts); protozoal diseases ( $n=5)$; intestinal infectious diseases $(n=5)$, mycoses $(n=4)$. Other causes $(n=11)$ were related to herpes zoster, infections of central nervous system, other bacterial diseases or infectious agents, TB of nervous system.

Of the hospitalisations for injury, poisoning and other consequences of external causes ( $\mathrm{n}=29,10.6 \%$ ), poisoning by drugs, medicines and biological substances was listed in 16 cases. Four were related to antiretrovirals; other substances included: non-steroidal anti-inflammatory drugs (NSAID), antiepileptic, sedative-hypnotic, antidepressants, psychostimulants, anticoagulants, calcium-channel blockers, antacids and anti-gastric secretion drugs, oxytocic drugs. Five of the hospitalisations due to poisoning were additionally recorded as intentional self-harm by self-poisoning with drugs/alcohol). Eight hospitalisations were related to complications of surgical and medical care including: infection or other procedure complications, and complications of internal orthopaedic prosthetic devices, implants and grafts. There were 19 injuryrelated causes (head, neck, thorax, abdomen, lower back, lumbar spine and pelvis, elbow and forearm, hip and thigh, knee and lower leg, ankle and foot and foreign body in the genitourinary tract).

For 27 (9.9\%) admissions for genitourinary diseases, documented causes were: diseases of the urinary system ( $\mathrm{n}=7$ including: urinary tract infections and urethral fistulas), renal tubule-interstitial diseases $(n=5)$; diseases of male genital organs $(n=5)$. Other causes included renal failure, urolithiasis, non-inflammatory disorders of female genital tract and glomerular disease.

There were 25 hospitalisations (9.1\%) related to neoplasms; almost all (87\% of causes) were malignant. The most common affected regions of those were: digestive organs $(n=10)$, ill-defined secondary and unspecified sites $(n=6)$, respiratory and intrathoracic organs $(n=4)$, genital 
organs ( $n=2$ female and $n=1$ male), Kaposi's sarcoma $(n=1)$, melanoma $(n=1)$, lip, oral cavity and pharynx $(n=1)$. Non-malignant neoplasms were documented for four admissions.

The remaining 12 ICD-10 categories were each mentioned in less than $9 \%$ of the total admissions (Fig. 1).

Of note, there were 11 hospitalisations related to mental health problems. Four were related to depressive episodes; three to use of alcohol, opioids or other stimulants; one to non-drug/alcohol induced delirium; four unspecified.

In total, 27 hospitalisations (10\%) had one or more AIDS-defining illness (ADI) documented: pneumonia ( $n=12)$; encephalopathy ( $\mathrm{n}=3$ ); mycobacterium avium complex $(n=2)$; lymphoma $(n=2)$; cryptococcal meningitis $(n=2)$; Kaposi sarcoma ( $n=2)$; pneumocystis pneumonia $(n=2)$; cytomegalovirus $(n=1)$; tuberculosis and toxoplasmosis $(n=1)$

\section{Characteristics of patients at admission}

At admission, median age was 52 years; median CD4 count was 510/ $\mu$; median CD4 nadir was 113/ $\mu$ l. Half (51\%) of hospitalised individuals had a previous AIDS diagnosis and 21\% had viral non-suppression (median viral load: 738 copies/ml, IQR:162 - 22,653) at admission).

For injury/poisoning, more women (28\%), particularly Black African women (21\%), were hospitalised compared to the proportion overall (17\% and $12 \%$ respectively). Infectious and genitourinary disease admissions had a higher proportion of heterosexual men (30\% respectively), particularly of Black African ethnicity, compared to other causes. Median age at hospitalisation was somewhat lower for injury/poisoning than the other common causes.

Individuals hospitalised for digestive, infectious diseases or neoplasms had lower median CD4 counts compared to other causes. A prior AIDS diagnosis was much less prevalent in those hospitalised for injury/poisoning (28\%) compared to other common causes and hospitalisations overall (51\%); similarly CD4 nadir was higher for the injury/poising cause. Almost half of individuals admitted for infectious diseases had detectable viral load at hospitalisation compared to $21 \%$ of individuals admitted overall. Individuals admitted for circulatory, respiratory or infectious diseases were more likely to be current smokers compared to other causes.

For ADI hospitalisations, the median (IQR) current and nadir CD4 counts at admission were 560 (339-700) and 69 (17-202) cells/ $\mu$ I respectively, 26 (96\%) were on ART and 11 (41\%) had viral load > 50 copies/ml. The median time since HIV diagnosis was 20 years (IQR:1326).

The median duration of hospitalisation was 5 days, varying from 4 to 8 across the seven common causes.

\section{Discussion}

The causes of hospitalisation among a cohort of PLHIV followed up from 2011 to 2018 were wide-ranging with the most common being circulatory, digestive, respiratory, infectious diseases, injury/poisoning, genitourinary diseases and neoplasms in that order. AIDS-defining conditions accounted for $10 \%$ of hospitalisations.

Two other European studies of PLHIV in the contemporary era found infections were the most common cause of hospitalisation, with nonAIDS infections at least as common as AIDS-related. A French study in PLHIV in 2011 found that non-AIDS infections were the most common cause of hospitalisation (16.4\%), followed by HIV-related diseases (15.6\%) ${ }^{11}$. A Spanish study also found that infectious diseases (35\%, of which $36 \%$ were AIDS-related) were the most common causes of hospitalisation in $2003-13$, followed by digestive and respiratory diseases, hepatic decompensations, non-AIDS malignancies, psychiatric illnesses and cardiovascular diseases (CVD) ${ }^{12}$. A global systematic review among PLHIV focusing primarily on the period 2007-2015 found that the most common admission causes for adults were ADIs (31\% in Europe) and bacterial infections (27\% in Europe) in all geographic regions. Other common causes in Europe were respiratory (14\%), psychiatric (13\%), cardiovascular (12\%), renal (11\%), and liver diseases $(10 \%)^{7}$.

The spectrum of causes of hospitalisation in our study are similar to those found for mortality in PLHIV in recent studies in high income settings, ${ }^{13-15}$ including a study of 206 deaths of PLHIV in London in 2016, suggesting a similar underlying pattern of morbidity not dominated by AIDS-defining illnesses ${ }^{13}$.

In comparison to the 2018/19 National Health Service England data on hospitalisation in the general population, infections and circulatory disease admissions accounted for a larger proportion in our study of PLHIV, while pregnancy and childbirth were less common, which is expected given the lower proportion of women. Digestive diseases, neoplasms, respiratory diseases, injury/poisoning, circulatory, genitourinary and musculoskeletal diseases, and symptoms, signs and abnormal clinical findings, were among the top ten causes both in our study and in the general population, with some difference in relative importance ${ }^{16}$. Although the comparison is complicated by demographic 
differences, this suggests the pattern of morbidity causing hospitalisation is broadly similar in PLHIV as in the general population, with persisting differences in admissions for infectious diseases.

Half of individuals in our study had previous AIDS at hospitalisation; this percentage was particularly high for admissions with infectious diseases as a cause, but was also over $50 \%$ for circulatory, digestive, respiratory, and neoplasm causes. Overall, $43 \%$ of those hospitalised had previous AIDS at baseline compared to $34 \%$ in the whole study population. Our previous findings showed that baseline CD 4 nadir predicted hospitalisation in this population ${ }^{10}$. The potential long-lasting effects of immunosuppression on a range of morbidities reinforces the importance of timely diagnosis and treatment for HIV.

The rate of hospitalisation of 5.8/100 person-years in our study population was lower than some other recent studies in other high income settings ${ }^{11,17,18}$. Our study population included a low proportion of individuals with recent diagnosis (3.6\% diagnosed within one year) for whom hospitalisation rates are particularly high ${ }^{19}$.

Hospitalisations occurring at hospitals other than the Royal Free may have been missed if not reported to the HIV physician by the patient, general practitioner or hospital, or if this information was not documented. ASTRA participants may differ from non-participants with respect to levels and patterns of morbidity.

In summary, in the contemporary cART era, the spectrum of causes for hospitalisation in PLHIV in the UK highlights the importance of holistic care, including the prevention, early detection and treatment of common chronic conditions. 
Table 1

Characteristics of individuals at time of hospitalisation, number of emergency admissions and duration of hospital stay according to most common causes.

\begin{tabular}{|c|c|c|c|c|c|c|c|c|}
\hline \multirow[b]{2}{*}{ Characteristics } & \multicolumn{8}{|c|}{ ICD-10 classified cause of hospitalisation: 7 most common causes and total } \\
\hline & $\begin{array}{l}\text { Circulatory } \\
\text { diseases }\end{array}$ & $\begin{array}{l}\text { Digestive } \\
\text { diseases }\end{array}$ & $\begin{array}{l}\text { Respiratory } \\
\text { diseases }\end{array}$ & $\begin{array}{l}\text { Infectious } \\
\text { and } \\
\text { parasitic } \\
\text { diseases }\end{array}$ & $\begin{array}{l}\text { Injury/poisoning } \\
\text { /other external } \\
\text { causes }\end{array}$ & $\begin{array}{l}\text { Genitourinary } \\
\text { diseases }\end{array}$ & Neoplasms & $\begin{array}{l}\text { Total } \\
\text { admissions }\end{array}$ \\
\hline $\mathbf{N}$ & 46 & 36 & 32 & 30 & 29 & 27 & 25 & 274 \\
\hline Demographic & $34(74 \%)$ & $27(75 \%)$ & $21(66 \%)$ & $19(63 \%)$ & $16(55 \%)$ & $13(48 \%)$ & $17(68 \%)$ & $175(64 \%)$ \\
\hline group & $0(0 \%)$ & $2(5.6 \%)$ & $0(0 \%)$ & $4(13 \%)$ & $0(0 \%)$ & $4(15 \%)$ & $1(4.0 \%)$ & $14(5.1 \%)$ \\
\hline & $7(15 \%)$ & $5(14 \%)$ & $5(16 \%)$ & $5(17 \%)$ & $5(17 \%)$ & $4(15 \%)$ & $3(12 \%)$ & $38(14 \%)$ \\
\hline $\begin{array}{l}\text { Black African } \\
\text { heterosexual }\end{array}$ & $0(0 \%)$ & $1(2.8 \%)$ & $0(0 \%)$ & $1(3.3 \%)$ & $2(6.9 \%)$ & $2(7.4 \%)$ & $2(8 \%)$ & $14(5.1 \%)$ \\
\hline $\begin{array}{l}\text { Other } \\
\text { heterosexual } \\
\text { men }\end{array}$ & $5(11 \%)$ & $1(2.8 \%)$ & $6(19 \%)$ & $1(3.3 \%)$ & $6(21 \%)$ & $4(15 \%)$ & $2(8 \%)$ & $33(12 \%)$ \\
\hline $\begin{array}{l}\text { Black African } \\
\text { women }\end{array}$ & & & & & & & & \\
\hline Other women & & & & & & & & \\
\hline $\begin{array}{l}\text { Median age } \\
(\text { IQR })^{\star}\end{array}$ & $\begin{array}{l}56(46- \\
64)\end{array}$ & $\begin{array}{l}52(46- \\
58)\end{array}$ & $53(47-67)$ & $\begin{array}{l}54(45- \\
60)\end{array}$ & $48(43-59)$ & $53(46-60)$ & $54(48-60)$ & $52(46-60)$ \\
\hline $\begin{array}{l}\text { Median CD4 } \\
\text { count in cells// } \\
\mu l(\mathrm{IQR})^{\star}\end{array}$ & $\begin{array}{l}511(343- \\
804)\end{array}$ & $\begin{array}{l}340 \\
(272- \\
620)\end{array}$ & $\begin{array}{l}465(347- \\
753)\end{array}$ & $\begin{array}{l}378 \\
(170- \\
660)\end{array}$ & $525(449-696)$ & $\begin{array}{l}528(356- \\
893)\end{array}$ & $\begin{array}{l}410(267- \\
608)\end{array}$ & $\begin{array}{l}510(315- \\
739)\end{array}$ \\
\hline $\begin{array}{l}\text { Median CD4 } \\
\text { count nadir } \\
\text { cells/ } \mu \mathrm{l}(\mathrm{IQR}) *\end{array}$ & $\begin{array}{l}60(39- \\
250)\end{array}$ & $\begin{array}{l}102(44- \\
133)\end{array}$ & $\begin{array}{l}65(12- \\
185)\end{array}$ & $\begin{array}{l}59(18- \\
138)\end{array}$ & $202(50-280)$ & $\begin{array}{l}117(26- \\
147)\end{array}$ & $\begin{array}{l}74(14- \\
153)\end{array}$ & $\begin{array}{l}113(40- \\
239)\end{array}$ \\
\hline $\begin{array}{l}\text { Virally non- } \\
\text { suppressed (> } \\
50 \text { copies } / \mathrm{ml}) \text { * }\end{array}$ & $3(7 \%)$ & $5(14 \%)$ & $9(28 \%)$ & $14(47 \%)$ & $8(28 \%)$ & $3(11 \%)$ & $8(32 \%)$ & $57(21 \%)$ \\
\hline $\begin{array}{l}\text { Median years } \\
\text { since HIV } \\
\text { diagnosis } \\
(\mathrm{IQR})^{\star}\end{array}$ & $\begin{array}{l}20(11- \\
25)\end{array}$ & $\begin{array}{l}17(13- \\
24)\end{array}$ & $17(11-26)$ & $\begin{array}{l}15(13- \\
20)\end{array}$ & $12(8-22)$ & $17(13-23)$ & $21(13-26)$ & $18(11-23)$ \\
\hline $\begin{array}{l}\text { Currently not on } \\
\text { ART* }\end{array}$ & $2(4.4 \%)$ & $0(0 \%)$ & $1(3.1 \%)$ & $3(10 \%)$ & $1(3.5 \%)$ & $1(3.7 \%)$ & $4(16 \%)$ & $13(4.7 \%)$ \\
\hline $\begin{array}{l}\text { Median years } \\
\text { since first } \\
\text { started ART } \\
(\text { IQR)* }\end{array}$ & $15(7-20)$ & $\begin{array}{l}15(11- \\
19)\end{array}$ & $14(9-19)$ & $\begin{array}{l}13(9- \\
17)\end{array}$ & $8(6-14)$ & $15(12-20)$ & $16(11-20)$ & $14(9-19)$ \\
\hline $\begin{array}{l}\text { Prior AIDS } \\
\text { diagnosis* }\end{array}$ & $31(67 \%)$ & 18 (50\%) & $18(56 \%)$ & $22(73 \%)$ & $8(28 \%)$ & $12(44 \%)$ & $14(56 \%)$ & $141(51 \%)$ \\
\hline Most recent & $19(41 \%)$ & $10(29 \%)$ & $14(44 \%)$ & $13(43 \%)$ & $10(36 \%)$ & $6(22 \%)$ & $6(24 \%)$ & $110(40 \%)$ \\
\hline status*** & $8(17 \%)$ & $12(35 \%)$ & $9(28 \%)$ & $8(27 \%)$ & $8(29 \%)$ & $6(22 \%)$ & $12(48 \%)$ & $69(26 \%)$ \\
\hline Current smoker & $19(41 \%)$ & $12(35 \%)$ & $9(28 \%)$ & $9(30 \%)$ & $10(36 \%)$ & $15(56 \%)$ & $7(28 \%)$ & $92(34 \%)$ \\
\hline $\begin{array}{l}\text { Ex-smoker } \\
\text { Never smoked }\end{array}$ & & $\begin{array}{l}\text { missing } \\
=2\end{array}$ & & & missing $=1$ & & & missing $=3$ \\
\hline $\begin{array}{l}\text { Emergency } \\
\text { hospitalisations }\end{array}$ & 37 (80\%) & 30 (83\%) & 31 (97\%) & 26 (87\%) & 24 (83\%) & 20 (74\%) & $10(40 \%)$ & $206(75 \%)$ \\
\hline
\end{tabular}

IQR = interquartile range; ART = antiretroviral therapy. *Defined from clinical records; **Defined from ASTRA questionnaire responses and classified according to the definition used for PLHIV by Public Health England ${ }^{20} ; * \star \star$ Defined from clinical records where available, otherwise defined from ASTRA questionnaire. 


\begin{tabular}{|c|c|c|c|c|c|c|c|c|}
\hline \multirow[b]{2}{*}{$\begin{array}{l}\text { Median } \\
\text { duration of } \\
\text { admission in } \\
\text { days (IQR) }\end{array}$} & \multicolumn{8}{|c|}{ ICD-10 classified cause of hospitalisation: 7 most common causes and total } \\
\hline & $6(3-8)$ & $\begin{array}{l}6(3.5- \\
10.5)\end{array}$ & $6(3-9)$ & $7(4-12)$ & $4(2-7)$ & $4(2-8)$ & $8(3-18)$ & $5(2-9)$ \\
\hline
\end{tabular}

\section{Declarations}

\section{Ethics approval and consent to participate}

Ethical approval for the ASTRA study was obtained from the North West London research ethics committee (10/H0720/70). Informed consent to participate in the ASTRA study was obtained from all participants. Basic consent to participate in the ASTRA study included permission to collect the latest CD4 count and HIV plasma viral load values (with dates) known to each participant and these details were recorded in the study log. Participants were also asked if they would consent to linkage of questionnaire data with their routine clinical data for this study over the next few years. They were told that this was an optional consent and that they could refuse and still participate in the questionnaire part of the study.

\section{Availability of data and materials}

Any personally identifiable data cannot be made publicly available to protect participants' privacy. All other relevant data are available upon request to the senior author (contact: f.lampe@ucl.ac.uk).

\section{Consent for publication}

Not applicable.

\section{Competing interests}

No conflicts of interest declared.

\section{Funding}

FL and CS received a BHIVA research award 2017 to fund this research. SR receives a Royal Free Charity scholarship to fund PhD research.

\section{Authors' contributions}

SMR, FCL and CJS conceived the idea for the analysis, with input from all authors. SMR drafted the analysis plan and conducted all analyses, with input from FCL and CJS. FCL, AJR, ANP, MAJ, LS, AM, ASp, SC originally conceived and designed the ASTRA study; AJR, JM, MAJ were responsible for data collection at the Royal Free Hospital. FCL, CS, SM, FB, MAJ, AJR, ANP designed the hospitalisation sub-study; CC, ASt were responsible for data collection. SMR drafted the first draft of the manuscript, and all authors provided substantive input into this and subsequent drafts.

\section{Acknowledgements}

We thank all study participants for their time and effort, and gratefully acknowledge the contributions of all the ASTRA clinic teams in recruitment and data collection.

ASTRA clinic teams at Royal Free Hospital: Alison Rodger; Margaret Johnson; Jeffrey McDonnell; Aderonke Adebiyi. ASTRA core team: Fiona Lampe; Alison Rodger; Andrew Speakman; Andrew Phillips. ASTRA data management: Andrew Speakman; Marina Daskalopoulou; Fiona Lampe. ASTRA advisory group: Lorraine Sherr; Simon Collins; Jonathan Elford; Alec Miners; Anne Johnson; Graham Hart; Anna-Maria Geretti; Bill Burman. CAPRA grant Advisory Board: Nick Partridge; Kay Orton; Anthony Nardone; Ann Sullivan.

Funding: The ASTRA study presents independent research funded by the National Institute for Health Research (NIHR) under its Programme Grants for Applied Research funding scheme (RP-PG-0608-10142). The views expressed in this paper are those of the authors and not necessarily those of the NHS, the NIHR or the Department of Health. The ASTRA Study Group acknowledges the support of the NIHR, through the Comprehensive Clinical Research Network.

\section{References}


1. Hogg RS, Heath KV, Yip B, Craib KJ, O'Shaughnessy MV, Schechter MT, et al. Improved survival among HIV-infected individuals following initiation of antiretroviral therapy. JAMA. 1998;279(6):450-4.

2. Palella FJ, Jr., Delaney KM, Moorman AC, Loveless MO, Fuhrer J, Satten GA, et al. Declining morbidity and mortality among patients with advanced human immunodeficiency virus infection. HIV Outpatient Study Investigators. N Engl J Med. 1998;338(13):853-60.

3. Nakagawa F, May M, Phillips A. Life expectancy living with HIV: recent estimates and future implications. Curr Opin Infect Dis. 2013;26(1):17-25.

4. Wandeler G, Johnson LF, Egger M. Trends in life expectancy of HIV-positive adults on antiretroviral therapy across the globe: comparisons with general population. Curr Opin HIV AIDS. 2016;11(5):492-500.

5. Deeks SG, Phillips AN. HIV infection, antiretroviral treatment, ageing, and non-AIDS related morbidity. BMJ. $2009 ; 338: a 3172$.

6. Wing EJ. HIV and aging. Int J Infect Dis. 2016;53:61-8.

7. Ford N, Shubber Z, Meintjes G, Grinsztejn B, Eholie S, Mills EJ, et al. Causes of hospital admission among people living with HIV worldwide: a systematic review and meta-analysis. Lancet HIV. 2015;2(10):e438-44.

8. Bellino S, Borghetti A, Lombardi F, Camoni L, Ciccullo A, Baldin G, et al. Trends of hospitalisations rates in a cohort of HIV-infected persons followed in an Italian hospital from 1998 to 2016. Epidemiol Infect. 2019;147:e89.

9. Speakman A, Rodger A, Phillips AN, Gilson R, Johnson M, Fisher M, et al. The 'Antiretrovirals, Sexual Transmission Risk and Attitudes' (ASTRA) study. Design, methods and participant characteristics. PLoS One. 2013;8(10):e77230.

10. Rein SM, Smith CJ, Chaloner C, Stafford A, Rodger AJ, Johnson M, et al. Prospective association of social circumstance, socioeconomic, lifestyle and mental health factors with subsequent hospitalisation over 6-7 year follow up in people living with HIV in the UK [submitted]. 2020.

11. Seng R, Mutuon P, Riou J, Duvivier C, Weiss L, Lelievre JD, et al. Hospitalization of HIV positive patients: Significant demand affecting all hospital sectors. Rev Epidemiol Sante Publique. 2018;66(1):7-17.

12. Meijide H, Mena A, Rodriguez-Osorio I, Pertega S, Castro-Iglesias A, Rodriguez-Martinez G, et al. Trends in hospital admissions, readmissions, and in-hospital mortality among HIV-infected patients between 1993 and 2013: Impact of hepatitis C co-infection. Enferm Infecc Microbiol Clin. 2017;35(1):20-6.

13. Croxford S, Miller RF, Post FA, Harding R, Lucas SB, Figueroa J, et al. Cause of death among HIV patients in London in 2016. HIV Med. 2019;20(9):628-33.

14. Smith CJ, Ryom L, Weber R, Morlat P, Pradier C, Reiss P, et al. Trends in underlying causes of death in people with HIV from 1999 to 2011 (D:A:D): a multicohort collaboration. Lancet. 2014;384(9939):241-8.

15. Weber R, Ruppik M, Rickenbach M, Spoerri A, Furrer H, Battegay M, et al. Decreasing mortality and changing patterns of causes of death in the Swiss HIV Cohort Study. HIV Med. 2013;14(4):195-207.

16. NHS Digital. Hospital Admitted Patient Care and Adult Critical Care Activity 2018-19. Health and Social Care Information Centre; 2019.

17. Lazar R, Kersanske L, Xia Q, Daskalakis D, Braunstein SL. Hospitalization Rates Among People With HIV/AIDS in New York City, 2013. Clin Infect Dis. 2017;65(3):469-76.

18. Davy-Mendez T, Napravnik S, Wohl DA, Durr AL, Zakharova O, Farel CE, et al. Hospitalization Rates and Outcomes among Persons Living with HIV in the Southeastern United States, 1996-2016. Clin Infect Dis. 2019.

19. Rein S, Lampe F, Johnson M, Bhagani S, Miller R, Chaloner C, et al. All-cause hospitalisation according to demographic group in people living with HIV in the current ART era: Recent findings from a cohort study in the UK [in press]. 2020.

20. Public Health England (PHE). Trends in new HIV diagnoses and in people receiving HIV-related care in the United Kingdom: data to the end of December 2018. London; 2019.

\section{Figures}




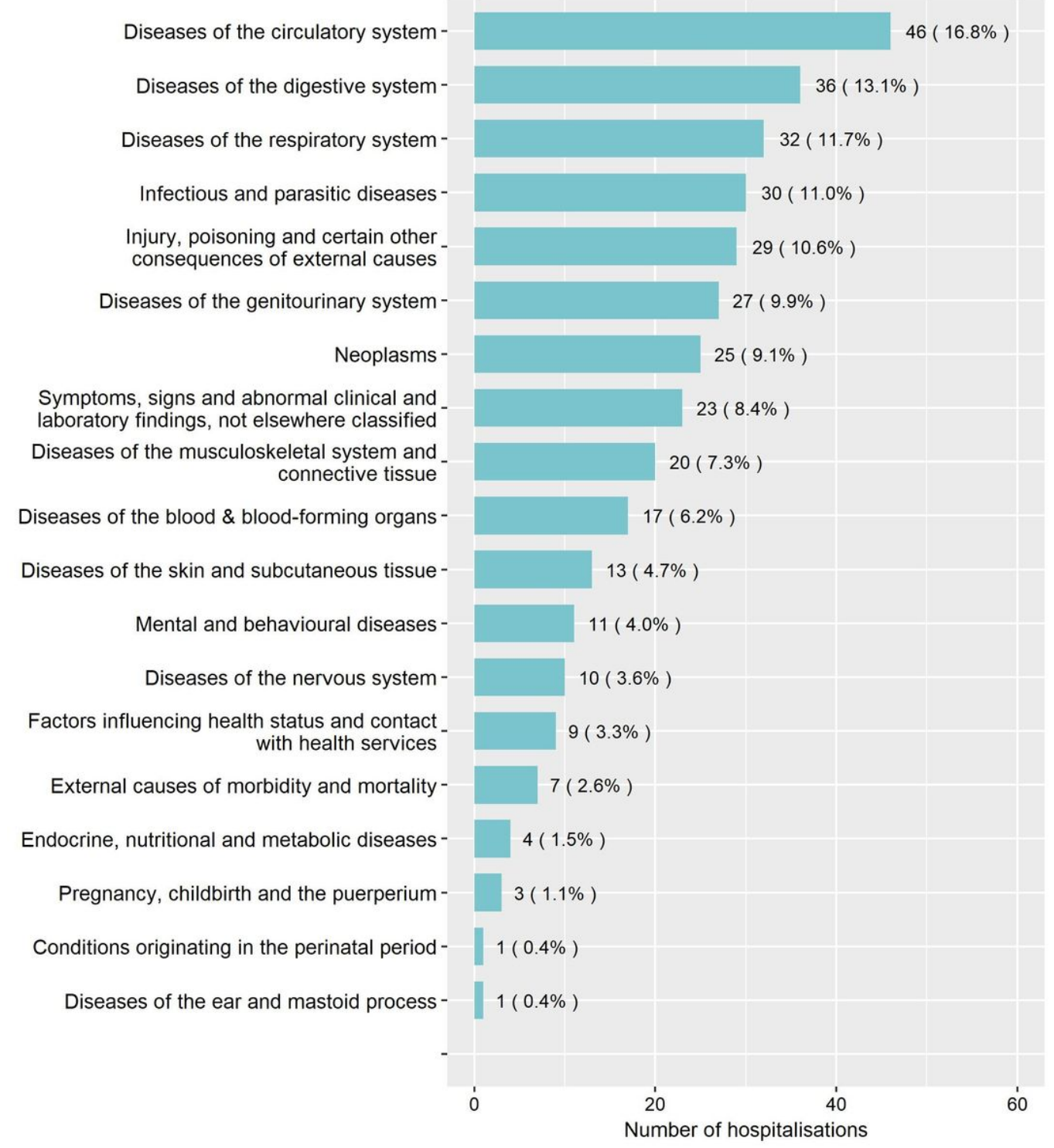

Figure 1

Number and percentage of hospitalisations related to each class of ICD-10 classified causes (denominator is the total number of hospitalisations). Percentages sum to $>100 \%$ as multiple causes could be documented for a single hospitalisation.

\section{Supplementary Files}

This is a list of supplementary files associated with this preprint. Click to download.

- AstraFEMALEpress240111.pdf

- AstraMALEpress240111.pdf 